\title{
Light-Induced Passivation of Si by lodine Ethanol Solution
}

Conference Paper NREL/CP-520-44999

February 2009

\section{Preprint}

B. Sopori, P. Rupnowski, J. Appel, and

D. Guhabiswas

National Renewable Energy Laboratory

L. Anderson-Jackson

North Carolina Agricultural and Technical State University

Presented at the Materials Research Society (MRS)

Fall Meeting 2008

Boston, Massachusetts

December 1-5, 2008

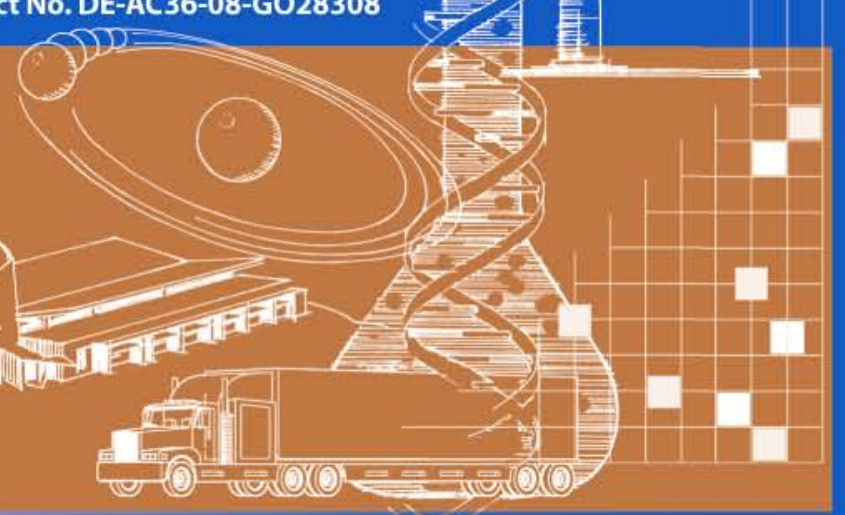




\section{NOTICE}

The submitted manuscript has been offered by an employee of the Alliance for Sustainable Energy, LLC (ASE), a contractor of the US Government under Contract No. DE-AC36-08-GO28308. Accordingly, the US Government and ASE retain a nonexclusive royalty-free license to publish or reproduce the published form of this contribution, or allow others to do so, for US Government purposes.

This report was prepared as an account of work sponsored by an agency of the United States government. Neither the United States government nor any agency thereof, nor any of their employees, makes any warranty, express or implied, or assumes any legal liability or responsibility for the accuracy, completeness, or usefulness of any information, apparatus, product, or process disclosed, or represents that its use would not infringe privately owned rights. Reference herein to any specific commercial product, process, or service by trade name, trademark, manufacturer, or otherwise does not necessarily constitute or imply its endorsement, recommendation, or favoring by the United States government or any agency thereof. The views and opinions of authors expressed herein do not necessarily state or reflect those of the United States government or any agency thereof.

Available electronically at http://www.osti.gov/bridge

Available for a processing fee to U.S. Department of Energy and its contractors, in paper, from:

U.S. Department of Energy

Office of Scientific and Technical Information

P.O. Box 62

Oak Ridge, TN 37831-0062

phone: 865.576 .8401

fax: 865.576 .5728

email: mailto:reports@adonis.osti.gov

Available for sale to the public, in paper, from:

U.S. Department of Commerce

National Technical Information Service

5285 Port Royal Road

Springfield, VA 22161

phone: 800.553.6847

fax: 703.605.6900

email: orders@ntis.fedworld.gov

online ordering: http://www.ntis.gov/ordering.htm 


\title{
Light-Induced Passivation of Si by Iodine Ethanol Solution
}

\author{
Bhushan Sopori ${ }^{1}$, Przemyslaw Rupnowski ${ }^{1}$, Jesse Appel ${ }^{1}$, Debraj Guhabiswas ${ }^{1}$, LaTecia \\ Anderson-Jackson ${ }^{2}$ \\ ${ }^{1}$ National Renewable Energy Laboratory, Golden, CO 80401 \\ ${ }^{2}$ North Carolina Agricultural and Technical State University, Greensboro, NC, 27411
}

\begin{abstract}
We report on our observations of light-activated passivation (LIP) of Si surfaces by iodine-ethanol (I-E) solution. Based on our experimental results, the mechanism of passivation appears to be related to dissociation of iodine by the photo-carriers injected from the Si wafer into the I-E solution. The ionized iodine $\left(\mathrm{I}^{-}\right)$then participates in the formation of a Si-ethoxylate bond that passivates the Si surface. Experiments with a large number of wafers of different material parameters indicate that under normal laboratory conditions, LIP can be observed only in some samples - samples that have moderate minority-carrier lifetime. We explain this observation and also show that wafer cleaning plays an extremely important role in passivation.
\end{abstract}

\section{INTRODUCTION}

It is well recognized that iodine-ethanol (I-E) or iodine-methanol (I-M) solutions can passivate Si surfaces [1-9]. This method of surface passivation can be very valuable when a temporary and removable passivation of a Si wafer surface(s) is needed. The most common application of a temporary passivation is for making lifetime measurements of Si wafers, where a very high-quality surface passivation is needed to measure the bulk lifetime, $\tau_{\mathrm{b}}$. This is a preferred method of passivation because, unlike other techniques of passivation such as deposition of nitride, oxide, or an $\mathrm{n} / \mathrm{p}$ junction, I-E passivation is achieved at room temperature without any high-temperature wafer processing. Unfortunately, the mechanism of passivation is not well understood. As a result, it is a common experience that measurements made with I-E (IM) solution are not reproducible. Earlier studies to investigate sources of these variations have shown that measurement is influenced by wafer cleaning [3,7,10]. Furthermore, Refs. [3,7] have shown that multiple cleaning of wafers leads to an improved passivation. Recently, we developed a procedure for wafer cleaning that yields highly reproducible values of minoritycarrier lifetime as measured by photo-conductance decay (PCD) or quasi-steady-state photoconductance (QSSPC) techniques. This cleaning procedure involves cleaning the wafer in Piranha, followed by a low-temperature oxidation and a hydrofluoric (HF) dip to remove a thin layer from the surface [7].

Because our new procedure enabled reproducible measurement of lifetime, it led to the discovery of another source of variability in lifetime measurement - the influence of lightexposure on the passivation produced by I-E. We observed that surface passivation is greatly hastened if the Si wafer, immersed in I-E solution, is exposed to light [10]. Here, we present a mechanism of passivation by I-E solution, which also explains the results presented in this paper on the dependence of passivation on the light illumination. In particular, we explain a very 
intriguing feature as to why only some wafers exhibit light dependence of the measured lifetime on light exposure. We will first briefly describe our experiment approach, including the improved cleaning procedure that has allowed us to achieve repeatable results and concomitantly allowed us to identify the light dependence.

\section{EXPERIMENTAL DETAILS}

Surface passivation was determined indirectly through the measurement of the minoritycarrier lifetime. It is known that measured lifetime $\left(\tau_{\mathfrak{m}}\right)$ of a Si wafer can be expressed as: $1 / \tau_{\mathrm{m}}$ $=1 / \tau_{\mathrm{b}}+\mathrm{SRV} / 2 \mathrm{~W}$, where $\tau_{\mathrm{b}}, \mathrm{SRV}$, and $\mathrm{W}$ are the bulk lifetime, surface recombination velocity, and wafer thickness, respectively. Thus, for a given wafer of lifetime $\tau_{\mathrm{b}}$, the measured lifetime depends on the SRV. Because passivation reduces SRV, the passivation effect is manifested as an increase in the measured lifetime. Figure 1 shows effective lifetime, $\tau_{\mathrm{m}}$, for wafers of three different bulk lifetimes ( $10 \mu \mathrm{s}, 100 \mu \mathrm{s}$, and $1 \mathrm{~ms})$ as a function of SRV. It is seen that the SRV must be reduced to about $1 \mathrm{~cm} / \mathrm{s}$ to be able to measure the real $\tau_{\mathrm{b}}$ of a 1-ms-lifetime wafer. However, for a $10-\mu$ s wafer, the SRV on the order of $1000 \mathrm{~cm} / \mathrm{s}$ is sufficient. Hence, as is generally done, we also used the measurement of $\tau_{\mathrm{m}}$ as a parameter to derive the effectiveness of the passivation.

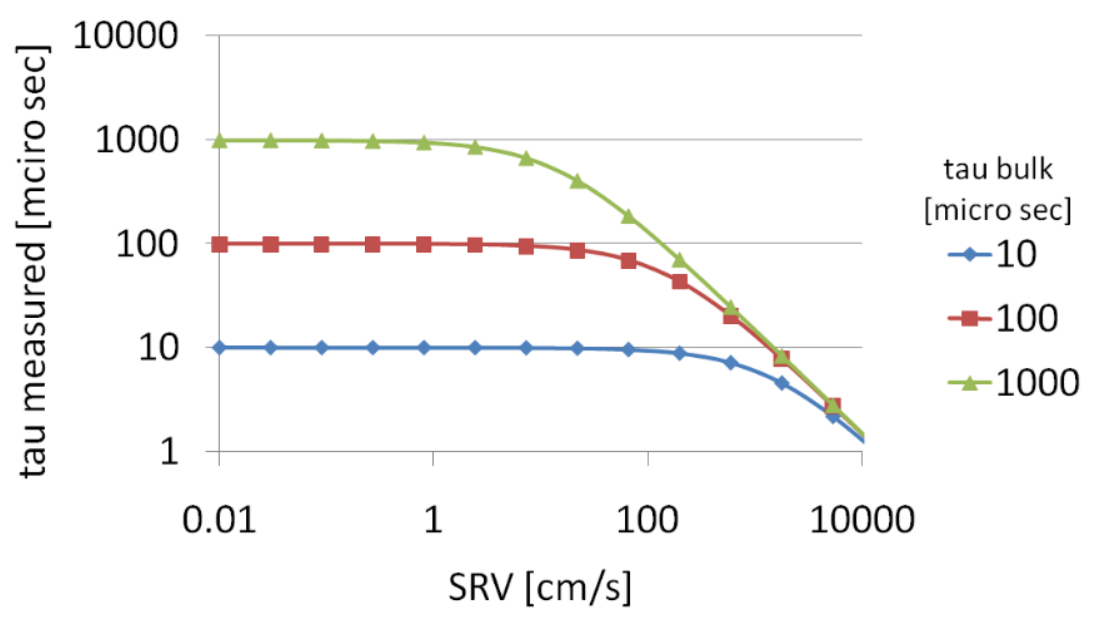

Figure 1. Dependence of measured lifetime, $\tau_{\mathrm{m}}$, on the actual bulk lifetime, $\tau_{\mathrm{b}}$, and surface recombination velocity, SRV.

This work was done primarily using single-side polished, single-crystal wafers within a large resistivity range of $1 \Omega$-cm to undoped. We used Czochralski (CZ) and float-zone (FZ) grown, both n-type and p-type wafers. The resistivity of each wafer was measured by four-point probe, and wafers were sorted into tight resistivity groups. Samples were cleaned using our recently developed cleaning procedure, placed in a polyethylene bag, and a few drops of I-E solution were placed on each side of the wafer. The bag was then allowed to collapse on the wafer and excess I-E was gently squeezed out. The wafer was then placed in a Sinton apparatus for measurement of $\tau_{\mathrm{m}}$. The Sinton machine allows different modes of measurement, which 
include QSSPC, transient PCD, and generalized PC. When calibrated properly, we found that in generalized mode the injection-level dependence of $\tau_{\mathrm{m}}$ was the same as measured by other modes. In view of this, we only describe the results measured by generalized PC. Passivation was determined simply on the basis of obtaining the highest lifetime value.

\section{WAFER CLEANING}

We (and other researchers) $[3,7,10]$ have shown that wafer cleaning plays a very important role in obtaining good surface passivation. We have determined that even in a very high-quality wafer it is necessary to remove a thin surface layer to get good passivation. We believe that this need arises because some of the impurities diffuse several tens of $\AA$ into the surface and that in the presence of impurities it is difficult to get surface passivation that is needed to measure lifetimes $>1 \mathrm{~ms}$. Although one can chemically etch a thin layer from a wafer surface, we found that a low-temperature optical oxidation, followed by an HF dip, can be very useful in removing a controlled layer from the surface. One important question is how deep a surface region must be removed or etched. To answer this question, we performed oxidation in steps to remove only about $75 \AA$ in each step. The sample was cleaned and oxidized before each set of measurements. Figure 2 depicts the time dependence of the lifetime measurements for the first three cleaning steps.

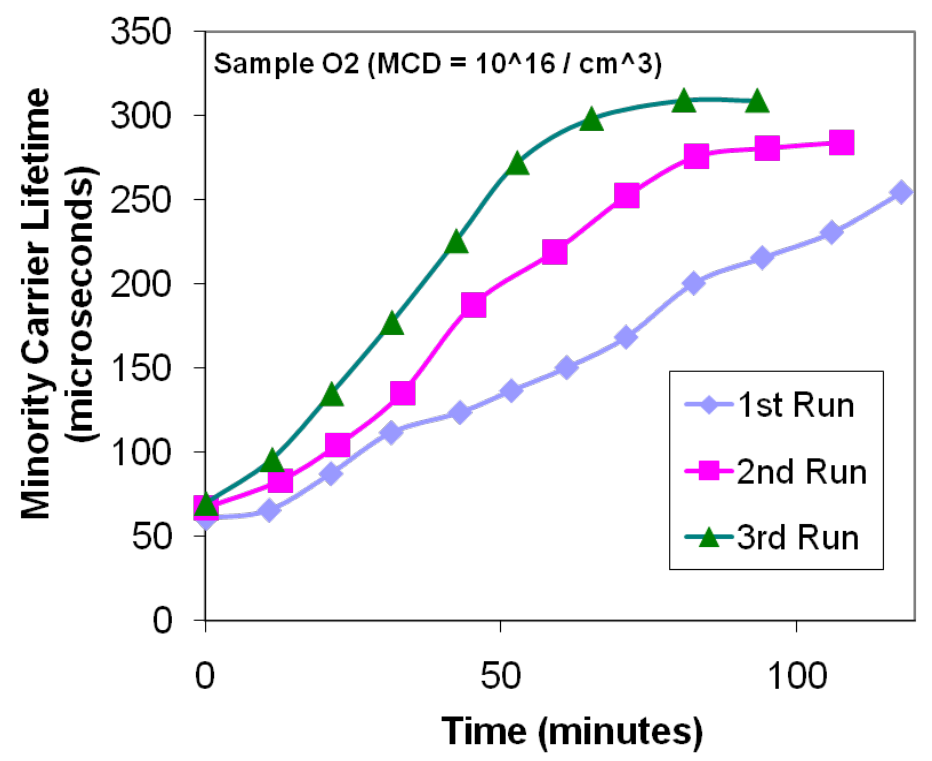

Figure 2. Time-dependence of $\tau_{\mathrm{B}}$ after including oxidation in the cleaning procedure, for sequential cleaning steps. Each oxidation run removed a surface layer that was about $75 \AA$ thick.

Figure 2 shows that surface cleanliness and its passivation are a function of total oxidation time. Based on this, we developed our procedure for wafer cleaning that consists of the following: (i) removal of organics by solvent cleaning followed by deionized (DI) water rinse, (ii) piranha $\left(\mathrm{H}_{2} \mathrm{SO}_{4}: \mathrm{H}_{2} \mathrm{O}_{2}\right.$ 2:1) cleaning at $80^{\circ} \mathrm{C}$, (iii) dilute $\mathrm{HF}$ rinse, DI water rinse, and nitrogen drying, (iv) oxidation in an optical furnace for $10 \mathrm{~min}$, and (v) dilute $\mathrm{HF}$ dip and $\mathrm{N}_{2}$ 
drying. Following this cleaning, the samples were placed in a polyethylene bag. We found that zip-lock bags provided an excellent way to passivate the sample. We tried a variety of bags of different qualities and thicknesses, and the most convenient was a 1-2-mil-thick polyethylene bag. A well-cleaned sample was placed in a polyethylene bag and covered on both sides with IE solution (typically of 0.1 molarity). Excess solution from each surface was squeezed out to leave a thin, uniform layer of the solution on the surface. In our measurements, the change in molarity of the solution between 0.01 and 0.1 did not influence the results. This cleaningpassivating procedure for lifetime measurement works very well and obtains highly reproducible results.

\section{LIGHT-ACTIVATED PASSIVATION}

Another feature of Figure 2 is that in each measurement it takes a long time before $\tau_{\max }$ (maximum value of $\tau_{\mathrm{m}}$ is reached. We also observed that if the measurements were done at shorter intervals, the slope of the curves increased. We concluded that the light from the tester itself was influencing the measurement by lowering the surface recombination velocity and concomitantly causing the $\tau_{\mathrm{m}}$ to increase. This interesting phenomenon indicates that the I-E surface passivation has a light-activated component. To confirm the light-induced passivation, we cleaned wafers (using our new oxidation procedure), placed them in an I-E bag, and exposed them to about 0.5 -sun intensity from a solar simulator for 15 minutes. We found that the lifetime tester yielded $\tau_{\max }$ immediately after the exposure; furthermore, there was a slow decrease (as shown in Figure 3a). We found that this decrease occurs for all wafers after the measured lifetime reached its maximum (see Figures $3 a$ and $3 b$ ).
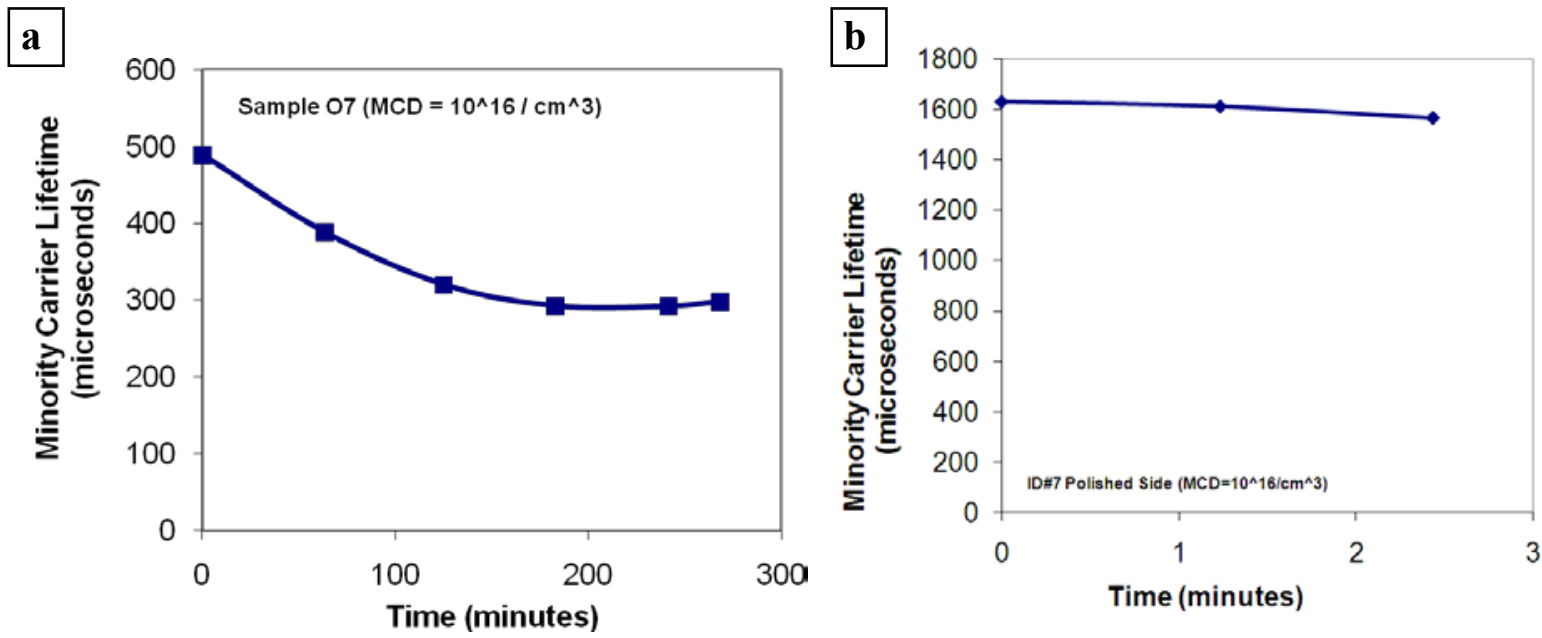

Figure 3. $\tau_{\mathrm{m}}$ decay after light exposure in solar simulator (a); the initial increase was not observed. Short-term variation of $\tau_{\mathrm{m}}$ for a long-lifetime wafer, (b).

Clearly, the light activation of passivation must be related to the chemistry of I-E. There is some published work [11-13] that proposes that the passivation of the Si surface is caused by tying up of silicon dangling bonds by the ethoxyl group, as illustrated in Figure 4. It has been proposed that this reaction is prompted by the dissociation of iodine. 


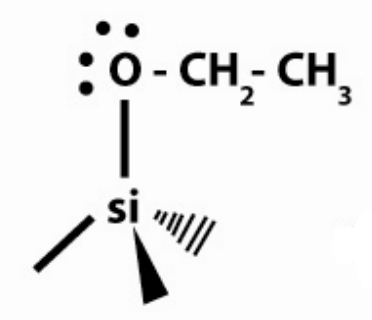

Figure 4. Silicon surface passivated with ethoxylated group.

We first wanted to verify this assumption. To do so, we prepared a set of samples and placed them in a solution containing ethanol only and measured the lifetime. Then these samples were illuminated with light. Next, iodine was introduced, followed by exposure to light from a solar simulator. Figures $5 \mathrm{a}$ and $5 \mathrm{~b}$ show typical results of the two groups. Both samples $\mathrm{O} 3$ (which exhibits LIP) and sample X14 (with no LIP effect) show that ethanol alone does not produce any passivation, even with illumination. It is clear that iodine is needed to produce passivation.
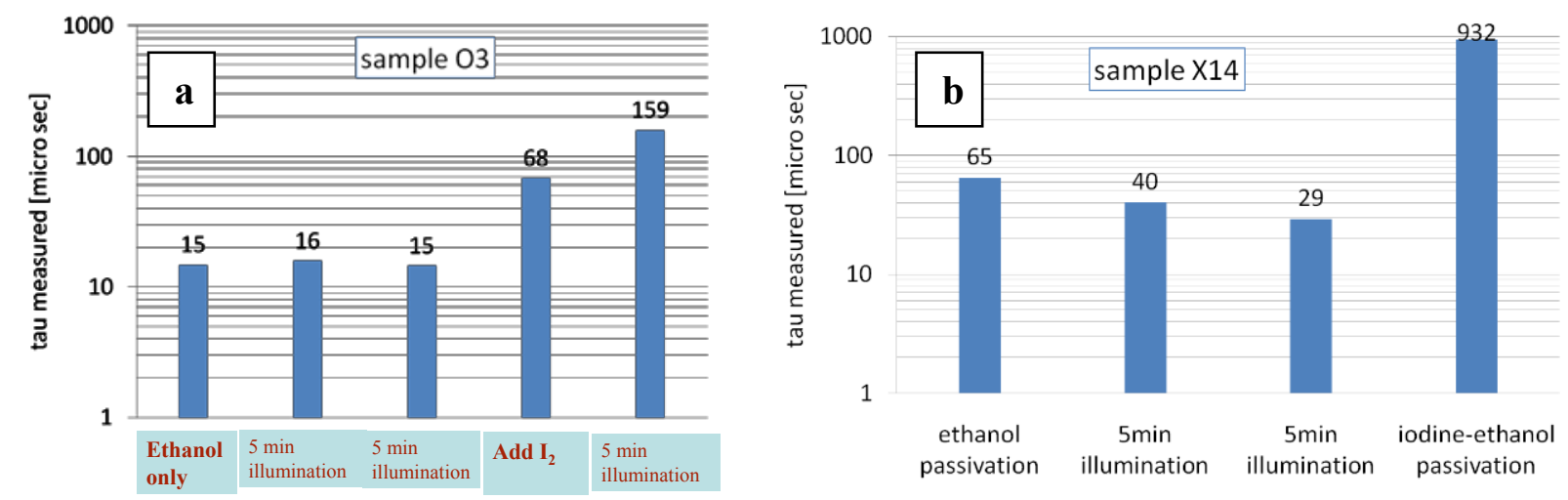

Figure 5. Effect of $I_{2}$ and illumination on a medium (a) and high (b) lifetime wafers.

Given that iodine is needed to produce passivation, it is possible that the ultraviolet (UV) component of light can cause dissociation of $\mathrm{I}_{2}$, and the atomic iodine can further promote formation of Si-ethoxylate bonding. This assumption was tested on several wafers by placing each cleaned wafer in the I-E bag and then exposing it to UV light. However, the lifetime did not reach $\tau_{\max }$, as seen in the results of Figure 6 . We also tried to determine if the effect was thermally induced because exposure of the wafer in the I-E bag caused it to heat up. Again, heating did not produce any change in the lifetime. Figure 6 elucidates the influence of various treatments on time dependence of the lifetime measured immediately after the treatment.

From the above results it is clear that surface passivation requires the presence of iodine. However, the results of Figure 6 show that iodine in methanol does not appear to dissociate rapidly by UV light, or perhaps there is a need to use higher light intensity. Only some wafers exhibit the effect of light in expediting the passivation process (as described), which suggests that passivation is related to some wafer parameter(s). We have attempted to relate LIP to material properties such as resistivity, oxygen content, carbon concentration, and other impurity levels. In this endeavor, we observed that the LIP effect was displayed by wafers that had $\tau_{\mathrm{b}}$ in the range of about 50 to $400 \mathrm{~ms}$ (medium-lifetime group). High-lifetime and low-lifetime wafers did not exhibit LIP. This ruled out the association of LIP with Fe. 


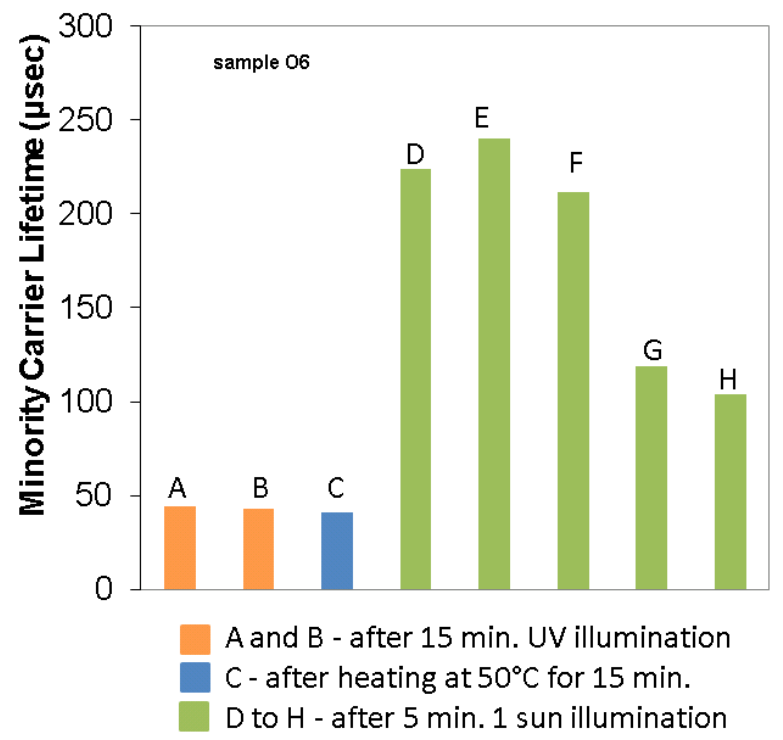

Figure 6. $\tau_{\mathrm{m}}$ of a p-type wafer, resistivity $27 \Omega$-cm measured after several treatments: UV for $15 \mathrm{~min}$ and $30 \mathrm{~min}$, heating, exposure to light for different times.

The mechanism of LIP appears to be related to carrier-induced dissociation of $\mathrm{I}_{2}$. When a wafer in contact with I-E solution is illuminated with light of a broad spectrum, there is a large increase in the minority-carrier concentration at the Si surface. For a p-type wafer, a high concentration of electrons will be available and some of them can be injected into the I-E solution, where they dissociate $\mathrm{I}_{2}$ producing $\mathrm{I}^{-}$species. The active $\mathrm{I}^{-}$can participate in converting a H-terminated surface (produced by HF dip performed just prior to I-E immersion) to an ethoxylate-terminated surface. The kinetics of passivation is illustrated in Figure 7. This reaction occurs in two phases. In phase 1, iodine simply acts as an oxidant. Because iodine is electronegative in nature, it has the ability to take in an extra electron to form ionized atomic iodine, $\mathrm{I}^{-}$. Thus, when photogenerated electrons are available at the $\mathrm{Si}-\mathrm{H}$ surface, $\mathrm{I}_{2}$ can form iodine anions $\left(\mathrm{I}^{-}\right)$. The electron flow to iodine leaves $\mathrm{Si}-\mathrm{H}$ in positively charged $[\mathrm{Si}-\mathrm{H}]^{+}$ionic form. In this situation, an ethoxyl nucleophile can easily attach itself to $\mathrm{Si}-\mathrm{H}$ via a coordinate bond, which occurs in the second phase. This occurrence is accompanied by release of hydrogen as a proton from the alcohol, leading to the charge neutrality of the five-coordinate Si species. Formation of five-coordinated $\mathrm{Si}$ in aqueous solutions is well known [11-13]. Next, the fivecoordinated Si loses an electron, which is captured by iodine, leading to a positively charged five-coordinated $\mathrm{Si}$. In the final step, the loss of another proton results in the formation of the final ethoxylated silicon surface.

The carrier-induced dissociation is likely to depend on the carrier concentration at the surface. The electron density at the surface depends strongly on the bulk lifetime of the wafer and its surface characteristics such as SRV. It is expected that carrier concentration at the surface of a long-lifetime wafer can be orders of magnitude higher than at the surface of a shortlifetime wafer. Hence, a long-lifetime wafer can get passivated even with low-intensity illumination, such as from room light. On the other hand, lower-lifetime material will require longer exposure to light. This explains why in our experiments that long-lifetime wafers, when properly processed, do not need simulator light for passivation. We believe that the same mechanism also applies to short-lifetime wafers. 

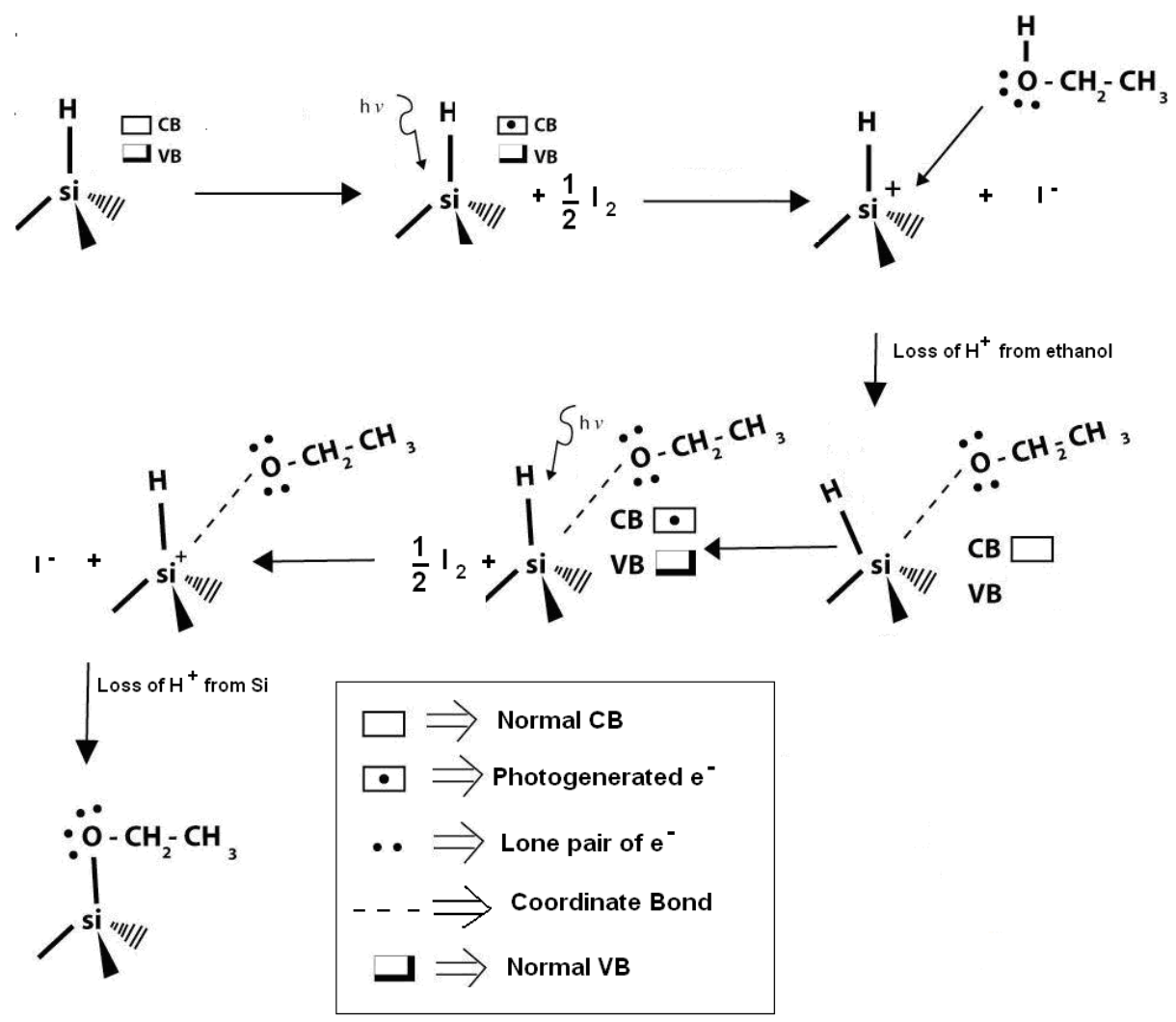

Figure 7. Proposed mechanism for passivation of silicon surface by I-E solution.

\section{CONCLUSIONS}

We presented experimental results showing that illumination of a silicon sample embedded in I-E solution causes optically induced enhancement of surface passivation. The mechanism of passivation appears to be related to dissociation of $\mathrm{I}_{2}$ into $\mathrm{I}^{-}$ions by the photogenerated carriers. We have proposed a detailed reaction outlining the participation of iodine and photo-generated electrons in producing a passivated Si surface terminated by ethoxylate groups. Our experiments indicate that generally good passivation of silicon wafers requires two essential steps: (i) wafer cleaning, which includes removal of about 200-300 $\AA$ of Si from each surface, and (ii) exposure of an I-E-passivated wafer to spectrum-rich light. We outlined a procedure that yields a very clean surface and have found that using fresh chemicals (piranha, $\mathrm{HF}$, and other acids) for each batch of wafers minimizes surface-quality variations. Our experience is that these chemicals have the propensity to acquire impurities from ambient and, in some cases, can leach them from the containers if very high-quality containers are not used. We suggest using optical oxidation after piranha cleaning.

\section{ACKNOWLEDGEMENTS}

This work was supported by the U.S. Department of Energy under Contract No. DE-AC3608GO28308 with the National Renewable Energy Laboratory. 


\section{REFERENCES}

1. A. G. Aberle, "Surface passivation of crystalline silicon solar cells: A review," Progress in Photovoltaics, vol. 8, pp. 473-487, Sep-Oct 2000.

2. T. Maekawa and Y. Shima, "Effect of steady bias light on carrier lifetime in silicon wafers with chemically passivated surfaces," Japanese Journal of Applied Physics Part 2 - Letters, vol. 35, pp. L133-L135, Feb 11996.

3. H. Msaad, J. Michel, A. Reddy, and L. C. Kimerling, "Monitoring and optimization of silicon surface quality," Journal of the Electrochemical Society, vol. 142, pp. 2833-2835, Aug 1995.

4. M. R. Page, Q. Wang, T. H. Wang, Y. Yan, S. W. Johnston, and T. F. Ciszek, "Silicon surface and heterojunction interface passivation studies by lifetime measurement," in $13^{\text {th }}$ Workshop on Crystalline Silicon Solar Cell Materials and Processes Vail, Colorado, 2003.

5. T. M. Renee et al., "Atomic-scale mechanistic study of iodine/alcohol passivated $\mathrm{Si}(100), "$ presented at $196^{\text {th }}$ Meeting of the Electrochemical Society, 1999.

6. N. A. Zarkevich and D. D. Johnson, "Energy scaling and surface patterning of halogenterminated Si(001) surfaces," Surface Science, vol. 591, pp. L292-L298, Oct 202005.

7. B. L. Sopori, P. Rupnowski, J. Appel, V. Mehta, C. Li, and S. Johnston, "Wafer preparation and iodine-ethanol passivation procedure for reproducible minority-carrier lifetime measurement," in $33^{\text {rd }}$ Photovoltaic Specialists Conference San Diego, CA, 2008.

8. T. S. Horányi, T. Pavelka, and P. Tüttö, "In situ bulk lifetime measurement on silicon with a chemically passivated surface," Applied Surface Science, vol. 63, pp. 306-311, 1993.

9. J. R. William, J. M. David, and S. L. Nathan, "Role of inversion layer formation in producing low effective surface recombination velocities at Si/liquid contacts," Applied Physics Letters, vol. 77, pp. 2566-2568, 2000.

10. G. J. Norga, M. Platero, K. A. Black, A. J. Reddy, J. Michel, and L. C. Kimerling, "Detection of metallic contaminants on silicon by surface sensitive minority carrier lifetime measurements," Journal of the Electrochemical Society, vol. 145, pp. 2602-2607, Jul 1998.

11. J. A. Haber and N. S. Lewis, "Infrared and X-ray photoelectron spectroscopic studies of the reactions of hydrogen-terminated crystalline $\mathrm{Si}(111)$ and $\mathrm{Si}(100)$ surfaces with $\mathrm{Br}-2, \mathrm{I}-2$, and ferrocenium in alcohol solvents," Journal of Physical Chemistry B, vol. 106, pp. 3639-3656, Apr 112002.

12. D. J. Michalak, S. Rivillon, Y. J. Chabal, A. Esteve, and N. S. Lewis, "Infrared spectroscopic investigation of the reaction of hydrogen-terminated, (111)-oriented, silicon surfaces with liquid methanol," Journal of Physical Chemistry B, vol. 110, pp. 20426-20434, Oct 2006.

13. S. D. Solares, D. J. Michalak, W. A. Goddard, and N. S. Lewis, "Theoretical investigation of the structure and coverage of the $\mathrm{Si}(111)-\mathrm{OCH} 3$ surface," Journal of Physical Chemistry B, vol. 110, pp. 8171-8175, Apr 2006. 


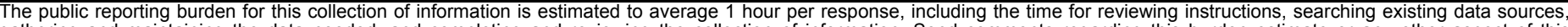

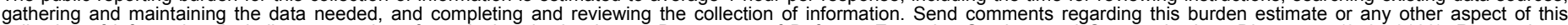

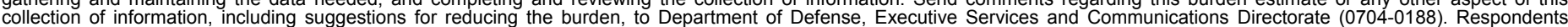

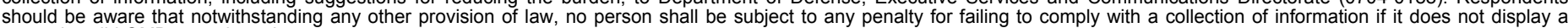

should be aware that notwithstanding

PLEASE DO NOT RETURN YOUR FORM TO THE ABOVE ORGANIZATION.

\section{REPORT DATE (DD-MM-YYYY) \\ February 2009}

4. TITLE AND SUBTITLE

Light-Induced Passivation of Si by lodine Ethanol Solution: Preprint
3. DATES COVERED (From - To)

December 1-5, 2008

5a. CONTRACT NUMBER

DE-AC36-08-GO28308

5b. GRANT NUMBER

5c. PROGRAM ELEMENT NUMBER

5d. PROJECT NUMBER

NREL/CP-520-44999

5e. TASK NUMBER

PVA93110

5f. WORK UNIT NUMBER

7. PERFORMING ORGANIZATION NAME(S) AND ADDRESS(ES)

National Renewable Energy Laboratory

1617 Cole Blvd. REPORT NUMBER

Golden, CO 80401-3393

NREL/CP-520-44999

9. SPONSORING/MONITORING AGENCY NAME(S) AND ADDRESS(ES)

10. SPONSOR/MONITOR'S ACRONYM(S) NREL

11. SPONSORING/MONITORING AGENCY REPORT NUMBER

12. DISTRIBUTION AVAILABILITY STATEMENT

National Technical Information Service

U.S. Department of Commerce

5285 Port Royal Road

Springfield, VA 22161

13. SUPPLEMENTARY NOTES

14. ABSTRACT (Maximum 200 Words)

We report on our observations of light-activated passivation (LIP) of Si surfaces by iodine-ethanol (I-E) solution. Based on our experimental results, the mechanism of passivation appears to be related to dissociation of iodine by the photo-carriers injected from the Si wafer into the I-E solution. The ionized iodine (I-) then participates in the formation of a Si-ethoxylate bond that passivates the Si surface. Experiments with a large number of wafers of different material parameters indicate that under normal laboratory conditions, LIP can be observed only in some samples-samples that have moderate minority-carrier lifetime. We explain this observation and also show that wafer cleaning plays an extremely important role in passivation.

15. SUBJECT TERMS

PV; light-induced passivation; silicon; iodine-ethanol; photo-conductance decay; wafer; nitride oxide; n/p junction; minority-carrier; lifetime; wafer cleaning;

\begin{tabular}{|c|c|c|c|c|}
\hline \multicolumn{3}{|c|}{ 16. SECURITY CLASSIFICATION OF: } & \multirow{2}{*}{$\begin{array}{l}\text { 17. LIMITATION } \\
\text { OF ABSTRACT } \\
\text { UL }\end{array}$} & \multirow{2}{*}{$\begin{array}{ll}\text { 18. } & \text { NUMBER } \\
\text { OF PAGES }\end{array}$} \\
\hline $\begin{array}{l}\text { a. REPORT } \\
\text { Unclassified }\end{array}$ & $\begin{array}{l}\text { b. ABSTRACT } \\
\text { Unclassified }\end{array}$ & $\begin{array}{l}\text { c. THIS PAGE } \\
\text { Unclassified }\end{array}$ & & \\
\hline
\end{tabular}

19a. NAME OF RESPONSIBLE PERSON

19b. TELEPHONE NUMBER (Include area code) 